\title{
Mechanical Characterization and Structural Attributes of Biohybrid Composites Derived Using Hemp, Bamboo, and Jute Fibres: an Alternative Approach in the Application of Natural Fibres in Automobile Parts
}

\author{
Rajmohan Bose - Arunachalam Kandavel \\ MIT Campus Anna University, India
}

In the present work, three natural fibres, namely jute, hemp and bamboo have been hybridized with seashell powder and polypropylene resin as biohybrid composites. Nine samples are considered for this study with various weight propositions of bamboo, hemp, and jute. The mechanical characteristics, such as the flexural, impact, and tensile strength of nine samples, are compared, and the Sample 9 shows very good results; the obtained flexural, tensile strength and impact energy of Sample 9 are $239.36 \mathrm{MPa}$, $47.84 \mathrm{MPa}$, and $18.33 \mathrm{~J}$, respectively. The main reason for this is the presence of jute material and layering pattern; Sample 9 contains 60 \% Jute, $20 \%$ hemp, and $20 \%$ bamboo; the percentage of jute is high compared to the other eight samples. Furthermore, morphological analysis and thermogravimetric analysis (TGA) have been carried out with Sample 9. While comparing the properties of with the existing dashboard material properties, they show more desirable values and thus, the compositions of Sample 9 material can be used for various vehicle parts. When the experimental results are compared with the finite element analysis (FEA) results, the experimental results match with the FEA results, and few variations are noticed.

Keywords: thermogravimetric analysis; morphological analysis; jute; hemp; bamboo, finite element analysis.

\footnotetext{
Highlights

- This Investigation has considered three natural fibres (hemp, bamboo, and jute) with seashell powder and polypropylene resin, and they are hybridized in biohybrid composites.

- Experimentally, its potential is investigated through various mechanical characteristics, such as tensile, flexural strength, and impact energy.

- The authors have also validated the reported results with FEA modelling.
}

\section{INTRODUCTION}

Naturally, derived cellulose fibres have gained significant attention due to their diverse applications in the engineering disciplines, and especially in end uses, such building materials and structural parts of motor vehicles for which there is a need for a lightweight material. Low cost followed by lesser tool wear at the time of processing are some of the major advantages seen during the implementation of plant fibres, as well as the ease of recycling an environmentally viable and friendly material. Over 1000 different plant species bearing cellulose-based usable fibres exist [1]. There is a growing consciousness of environmental sustainability and a profound interest among researchers in using natural fibres (NF) like bamboo, pineapple leaf, hemp, kenaf, banana, jute, coir, sisal, oil palm, and flax as green reinforcements of polymer composites for minimizing the overall implementation and of synthetic fibres, such as Kevlar, glass, and carbon [2].

The recent decade has seen the rise of the utilization of NF as a reinforcement concerning composite materials for replacing glass fibres. The automotive industry remains one of the promising and prominent users of naturally derived composites in their fabrication and interior applications, especially in the making of trunk liners and door panels for vehicles [3]. It is estimated that the increase in the utilization of $\mathrm{NF}$ as an alternative for several automotive components might reach about $54 \%$, since European and US car manufacturers have implemented Environmental Directives. Several US-based automotive have embraced using natural materials: about 1.5 million vehicles are already using vegetable fibres such as jute, hemp and kenaf as reinforcement of thermoplastic and thermosetting polymers [4]. Under this particular aspect, automobile parts like bumpers, panels, and other related automotive components are produced using fibres or with other forms of biothermoplastic as well as hybrid composites, which are already in use [5]. Composite materials involve a combination of two or even more differently derived materials for their effective reinforcement in industrial application. They are broadly used in many major industries, including automotive, aerospace, marine and electric, which require light weight-to-strength ratios [6]. 
Bamboo (Bambusoideae) is a group of gigantic grass plants. It is estimated that there are about 2000 species of bamboo around the world [7]. There is a steady rise in the marketing of bamboobased products as well as their manufacturing has increased rapidly. This is especially attributed due to its effective application from being an unwanted bamboo particulate which is concentrated to develop micro-bamboo filler derived polymer composite; this happens to serve as a better opportunity in replacing it effectively as an NF for enhancing materials' property [8].

Furthermore, the plant is well-known for its excellent mechanical properties (MP) based on comparative mass and the distinct attributes of its unique physical structure [9]. The developed brake pads using seashell powder gave a better friction coefficient as the optimal value (0.48) falls within the class $\mathrm{G}(0.45$ to 0.55$)$ type of brake pads recommended for use by the Society of Automobile Engineers (SAE) [10]. It was found that poor binding with epoxy/natural filler, agglomeration issue under a higher filler weight $\%$, and also susceptible to increased moisture content [11]. Several types of research studies have analysed its effect on the recycling of polypropylene (PP), which is known as the most widely used matrix in terms of composite materials reinforced alongside natural fibres [12]. For instance, a study that concentrated on both the mechanical and rheological properties has shown that pure PP remains to be practically observed as unaffected while performing the first four recycling cycles. Also chemical treatments involving alkali, silane, and acid-based treatments have appeared to be the most utilized approaches in developing a fibre and natural filler [13].

Jute, which remains in the top the tables in terms of its usage as vegetable fibre, is grown in tropical countries like India, China, Bangladesh, Thailand, and Nepal. These countries collectively contribute $95 \%$ of global jute fibre production [14]. As the majority of studies focus on jute fibre/non-degradable polymer composites, research about jute/biodegradable polymer-based composites has been found to be quite limited [15]. For the hemp plant, the fibres contained within the tissues facilitate holding the plant in an erect position. Hence, the fibres exhibit strength as well as stiffness. Both of these factors make hemp quite suitable for the reinforcement of compositebased materials [16].

In this study, physical, chemical and MP of NF's properties observed [17] and [18]. The chemical, physical and MP of polymers properties observed [19]. Fibre type is commonly categorized based on its origin: plant, animal, or mineral. From these types, plant-based fibres are the most suitable to be used in composites with structural requirements. Furthermore, plant fibres can suitably be grown in many countries and can be harvested within short periods. The focus, for example, in Europe, has been on flax, whereas hemp, jute, ramie, kenaf, and sisal have been of greater interest in Asia. Generally, higher performance is achieved with the varieties of higher cellulose content and with cellulose microfibrils aligned more in the fibre direction. It tends to occur in blast fibres (e.g., flax, hemp, kenaf, jute, and ramie) that have higher structural requirements in providing support for the plant's stalk [20]. Researchers [21] have found that with the addition of chemically treated wood flour in PP (polypropylene), sustained improvement is obtained in composite's tensile strength.

The research study evaluates the overall environmental impact of alkaline-treated bamboo, jute, and hemp fibre on a PP matrix. Flexural, impact, and tensile characteristics, scanning electron microscope (SEM), Energy Dispersive X-ray (EDX), TGA and FEA analyses have been investigated to develop verified weight proportions and layering patterns of bio hybrid composites for applications suitable for automobile parts.

\section{EXPERIMENTAL PART}

\subsection{Fabrication of Specimen}

Compression moulding is a form of moulding that requires preheated moulding material that is initially mounted on an open, heated, mould -etched cavity. At the Indian Institute of Technology Madras, compression moulding is used to create these composites. The composites are made up of NF and PP in the ratio of 1:4. The weight composition of the composite produced are 100 grams of fibre, 400 grams of PP resin, and 5 grams of seashell powder. The conditions involved in fabricating the specimen are: time: 4 hours, stirring time: 45 minutes, pressure: 25 bar, and temperature: $75{ }^{\circ} \mathrm{C}$. The dimensions of the composite shape are $300 \mathrm{~mm} \times 300 \mathrm{~mm} \times 4$ $\mathrm{mm}$ (length $\times$ width $\times$ thickness). The bio hybrid composites are fabricated into nine different weight proportions and layering patterns. The weight composition is illustrated in Table 1. Four layers of bio-hybrid composite are fabricated at a defined orientation $\left(0^{\circ} \& 90^{\circ}\right)$.

These three fibres (hemp, jute, and bamboo) was purchased from Go Green Products, Chennai. PP resin was purchased from Vasavibala resins $(\mathrm{P}) \mathrm{Ltd}$, 
Chennai. Seashells are collected from the seashore and powdered using a ball-milling machine.

Table 1. Sample weight distribution

\begin{tabular}{lccc}
\hline Sample & Hemp [\%] & Bambo0 [\%] & Jute [\%] \\
\hline Sample 1 & 40 & 30 & 30 \\
\hline Sample 2 & 30 & 40 & 30 \\
\hline Sample 3 & 30 & 30 & 40 \\
\hline Sample 4 & 50 & 25 & 25 \\
\hline Sample 5 & 25 & 50 & 25 \\
\hline Sample 6 & 25 & 25 & 50 \\
\hline Sample 7 & 60 & 20 & 20 \\
\hline Sample 8 & 20 & 60 & 20 \\
\hline Sample 9 & 20 & 20 & 60 \\
\hline
\end{tabular}

\subsection{Chemical Treatment}

The purpose of chemically treating the NF is primarily the removal of lignin, waxy substances, pectin, and natural oils that coat the external portion of the fibrous cell wall. This initial treatment exposes fibrils, thereby giving a rough topographical surface for the fibre. Bleaching is carried out using sodium hydroxide $(\mathrm{NaOH})$ as it is commonly used chemical in cleaning/ bleaching plant fibres' efficiently. Also, the chemical modifies the finer structural characteristics in native cellulose I/II via alkalization [22]. Fibre treatments involving silane and alkali require treatment for increasing adhesion between hydrophilic groups endowed in NF with that of the hydrophobic epoxy matrix [23]. Interfacial bonding in the case of the fibre and matrix is found to have improved effectively via chemical treatment using a coupling agent [24]. In this study, alkaline treatment has been done with $5 \%$ $\mathrm{NaOH}$; the material is dipped in it for $72 \mathrm{hrs}$ and dried [25] and [26].

\subsection{Mechanical Characterization}

A universal testing machine (Instron 5567, Shakopee) has been employed to perform mechanical attributes, and elongation is performed under the breakage of composites under different loadings. Composite samples are cut into a rectangular shape of $246 \mathrm{~mm} \times$ $29 \mathrm{~mm} \times 4 \mathrm{~mm}$ with a band saw machine for tensile testing, which has been carried out as per ASTM D3039 standard involving cross-head speed $5 \mathrm{~mm} /$ min with gauge length spanning $50 \mathrm{~mm}$. Data on loading, displacement, and strains are acquired. The impact in terms of strengths from derived composites under varied loading are estimated using the FIT300-D machine. The samples are then cut into a rectangular shape of $64 \mathrm{~mm} \times 12.7 \mathrm{~mm} \times 4 \mathrm{~mm}$ using a band saw. V-notched specimens were further tested as per ASTM D256. Appropriate pendulum hammers of over $10 \mathrm{~kJ}$ are mounted. The analysis tool involves the calibration of energy followed by accurate determination showing the exact amount in terms of impact energy $[\mathrm{J} / \mathrm{m}]$ involved for the tests. The energy needed for breaking composite specimens in terms of toughness and average impact energy is determined. Flexural properties of composites are evaluated by involving bending (three-point) using a universal testing machine, as per ASTM D790 standards.

Furthermore, they are cut as per the standard dimension of $250 \mathrm{~mm} \times 25 \mathrm{~mm} \times 4 \mathrm{~mm}$. The machine is operated at a cross-head speed of $1 \mathrm{~mm} / \mathrm{min}$ with a support span-to-depth ratio involving 16:1. The existing material mechanical properties (tensile, flexural and impact) were obtained as per the same testing procedure followed by the experimentally tested mechanical properties of the nine samples.

\subsection{Scanning Electron Microscopy (SEM)}

SEM is facilitated for observing the morphological attributes of the experimental composites comprising of montmorillonite (MMT) based inorganic load. This form of analysis is essentially used for studying the surface characteristics of the composites via constructing three-dimensional images under high resolution with excellent depth in the field and no loss in image sharpness. The morphological features of the fractured sample from the composites are determined using QUANTA 200F - SAIF - IIT Madras.

\subsection{Energy Dispersive X-ray (EDX)}

EDX is an X-ray approach used to determine the elemental composition of materials. A QUANTA 200F - SAIF-IIT Madras SEM instrument has been used to perform this elemental analysis.

\subsection{Thermogravimetric Analysis (TGA)}

The TGA of polymers serves as a very effective technique for assessing thermal stability. Similar approaches employed are DGC, DTA, and derivatographic analysis [27] for a comparative study, especially for assessing the thermal behaviour of related categories of polymer samples, with each of its samples analysed via one or more of such methods involving identical experimental attributes. For instance, TGA is performed in air with an oxygen-free nitrogen composition. The process is 
carried out under varied thermal conditions/different heating rates. It is imperative to assess the polymeric samples under different thermal analyses under a given method based on numerous aspects [28]. The amount, as well as material particle size, is examined these factors influence the nature of the thermogram. Thermogravimetric readings monitor the speed of the recorder by noting modifications in terms of weight and shape of sample containers which impact thermogravimetric outcomes. The heating rates of the sample and the ambient atmosphere during the time of analysis are assessed. The information achieved from TGA is found to be complementary to the other methods mentioned above. The study employed TGA analysis via the Universal V4.5A TA instrument in CLRI, Chennai.

\subsection{Finite Element Analysis (FEA)}

This work [29] has focused on numerical modelling, and verification of the experiment results is performed with the compression of axially compressed honeycomb cores. The explicit standard simulation has offered good results for the first phase of the test, and the force calculated by the simulation is very close to the experimental tests.

The formula used for density calculation is:

$$
\begin{aligned}
\text { Density } & =\rho_{(A \times \% A)}+\rho_{(F)(B \times \% B)} \\
& +\rho_{(F)(C \times \% C)}+\rho_{(F)(D \times \% D)} .
\end{aligned}
$$

The density calculation is carried out using the fibre weight percentage and resin weight percentage.

In this formula, $\rho$ stands for density, $A$ refers to matrix material density. $B, C$ and $D$ denote the densities of each of the fibres.

Semi-empirical models have been successfully used to describe the characterization of composite materials. Rule-of-mixture models are commonly used to predict Young's modulus [30].

$$
E_{C}=E_{F} E_{M} /\left(E_{F} V_{M}+E_{M} V_{F}\right)
$$

In this equation, $E_{C}, E_{F}$, and $E_{M}$ are Young's modulus for the composites, matrix, and fibres respectively; $V_{F}$ and $V_{M}$ are the volume fractions of the fibres and matrix, respectively.

\section{RESULTS AND DISCUSSION}

The $5 \%$ sodium hydroxide alkaline treatment of NF has improved the biohybrid specimen's mechanical characterization, although the aforementioned treatment wipes out the dust and other impurities of the fibre. It is more convenient to obtain interfacial adhesion bonding among reinforcement and matrix. The reinforcement and matrix parameters have greatly influenced the mechanical attributes and performed an influential role in fabricating the biohybrid specimens. Furthermore, the seashell powder is acknowledged because it contributes to the improvement of the biohybrid specimen's mechanical properties and also helps to minimize the voids and cracks in the specimen.

The experimentally tested mechanical properties of the nine samples and the existing material are given in Table 2. The properties of the existing material are compared with the samples obtained with high values [31].

Table 2. Mechanical strength of composite samples

\begin{tabular}{lccc}
\hline Sample & $\begin{array}{c}\text { Tensile } \\
\text { strength [MPa] }\end{array}$ & $\begin{array}{c}\text { Flexural } \\
\text { strength [MPa] }\end{array}$ & $\begin{array}{c}\text { Impact } \\
\text { energy [J] }\end{array}$ \\
\hline Sample 1 & 31 & 167.99 & 13.16 \\
\hline Sample 2 & 28.79 & 107.14 & 14.16 \\
\hline Sample 3 & 28.53 & 150.94 & 11.33 \\
\hline Sample 4 & 24.53 & 94.05 & 21 \\
\hline Sample 5 & 33.20 & 132.42 & 15.16 \\
\hline Sample 6 & 40.59 & 184.23 & 16.83 \\
\hline Sample 7 & 34.30 & 132.73 & 14.83 \\
\hline Sample 8 & 35.82 & 178.02 & 18.33 \\
\hline Sample 9 & 47.84 & 239.36 & 18.33 \\
\hline Existing material & 18.1 & 68.2 & 3.6 \\
\hline
\end{tabular}

\subsection{Tensile Strength}

The results assessments of various mechanical characteristics of fabricated composite (jute, hemp, bamboo) with regard to tensile strength are summarized in Table 2 for better comparison. Significantly, it is revealed that the joint exists with dissimilarities in aspect ratio, and the varied material fibres affect the inborn property; thus, mechanical characteristics increase/decrease, when applied individually. It is observed that the tensile strength of Sample 9 appears high compared to other sample data. Stress rises linearly by concerning the rises in strain of composites. The least tensile strength of $24.54 \mathrm{MPa}$ is obtained in Sample 4 which has $50 \%$ hemp, $25 \%$ bamboo, and $25 \%$ jute, whereas Sample 9 has $20 \%$ hemp, $20 \%$ bamboo, and $60 \%$ jute. This shows the highest value of $47.85 \mathrm{MPa}$. Thus, by concerning the tensile strength, the maximum value is obtained in the combination in which the presence of jute is the 
highest as well as the layering pattern of the biohybrid composite.

\subsection{Flexural Strength}

The flexural resistance observed from the composites is shown in Table 2. The flexural strengths for samples establishes from the linear portion of the curve via defining load and equivalent displacement, which is also indicated in Sample 9 to exhibit the highest value compared to other composite samples; this sample has the fibre content of $20 \%$ hemp, $20 \%$ bamboo, and $60 \%$ jute. Sample 4 has a fibre content of $50 \%$ hemp, $25 \%$ bamboo and, $25 \%$ jute. Sample 4 has the lowest value, at $94.05 \mathrm{MPa}$, which is not even half of the maximum value obtained.

\subsection{Impact Energy}

The test is achieved by assessing the impact of capability under different composites. Impact energy aid in determining the material's toughness. It is regarded as one of the critical factors measuring the ability to absorb energy while the sample undergoes plastic deformation (PD). Brittle materials, for instance, exhibit low toughness as an effect of a smaller degree of undergoing PD. In the case of NF, it shows greater fibre/matrix strength as it does not facilitate energy being absorbed in interfaces. This loss of energy is established via the Charpy impact test machine. The absorbed energy under each specimen when impacted by heavy blow, and the resultant data are summarized in Table 2. Resin toughness compared to that of fibre strength as well as stiffness observed is regarded as a major parameter that influences composite's impact-resistant properties. It is seen that Sample 4 has exhibited high impact energy upon comparison with other composites; the energy absorbed is $21 \mathrm{~J}$. Sample 4, which shows a high impact value, has the fibre content of $50 \%$ hemp, 25 $\%$ bamboo, and $25 \%$ jute. Sample 9 has the secondhighest value at $18.83 \mathrm{~J}$.

\subsection{Comparison of Composite Material with Existing Material}

The highest tensile, flexural, and impact values obtained from the experiment are compared with the existing material for car dashboards are shown in Table 2. The major proposal of this study is to suggest a composite material made of NF for the manufacturing of various automobile interior parts. Thus, the car dashboard is selected as a proposal, and the properties are compared. The tensile strength of the existing material is $18.1 \mathrm{MPa}$, but the highest value obtained in Sample 9 is $47.85 \mathrm{MPa}$, which is $29.75 \mathrm{MPa}$ high. Thus, the proposed composite possesses a value 2.6 times more than the existing value. The flexural strength of the existing materials is $68.2 \mathrm{MPa}$, but the highest value obtained in Sample 9 is $239.36 \mathrm{MPa}$, which is $171.16 \mathrm{MPa}$ high. Thus, the proposed composite possesses a value which is 3.5 times more than the existing value. The impact energy of the existing material is $3.6 \mathrm{~J}$, but the highest value obtained in Sample 4 is $21 \mathrm{~J}$, which is $17.4 \mathrm{~J}$ higher than the existing material. Thus, the Sample 4 possesses a value which is of 5.83 times higher than the existing value.

\subsection{Morphological Analysis via SEM}

Morphological analysis has been performed via SEM. Sample 9 has exhibited better MP, which is evident from the observed samples selected for the morphological analysis. The prediction of macroscopic behaviour of composite materials is of fundamental and practical importance, as new composites are being developed continually for the automotive as well as aerospace industries, electronic packaging, thermal insulation, and many other applications [32]. There is an improvement in the interfacial adhesion between the matrix and coating; hence, the mechanical properties are attributes of the high strength cellulosic composite. SEM observations have allowed highlighting the different morphology of the surfaces [33]. A detailed analysis of the microstructure was carried out; it highlighted the predominant role of fibre orientation in the MP of composites [34]. It was found that chemical treatment results in composites with better MP's compared to the composites without any treatments [35].

Fig. 1 displays a micrograph of a fractured specimen of tensile, flexural, and impact test of Sample 9, which shows improved MP related to other samples. Alkaline treatment of the composites aids in better interfacial bonding, which in turn improves the mechanical strength. Pull-out phenomena of the fibres are presented in the image. The SEM images reveal some voids due to the fibre pull-out, and more breakages of fibres. SEM images Fig. $1 b$ to $d$ indicates better fibre-matrix interaction between the fibres and the polymer matrix. Fig. 1a depicts the SEM image of the parent material; it clearly shows the fibre direction. It also demonstrates a very good bonding between the resins and fibre, thus indicating a better mechanical bonding with the fibre-polymer matrix. Fig. $1 \mathrm{~b}$ 

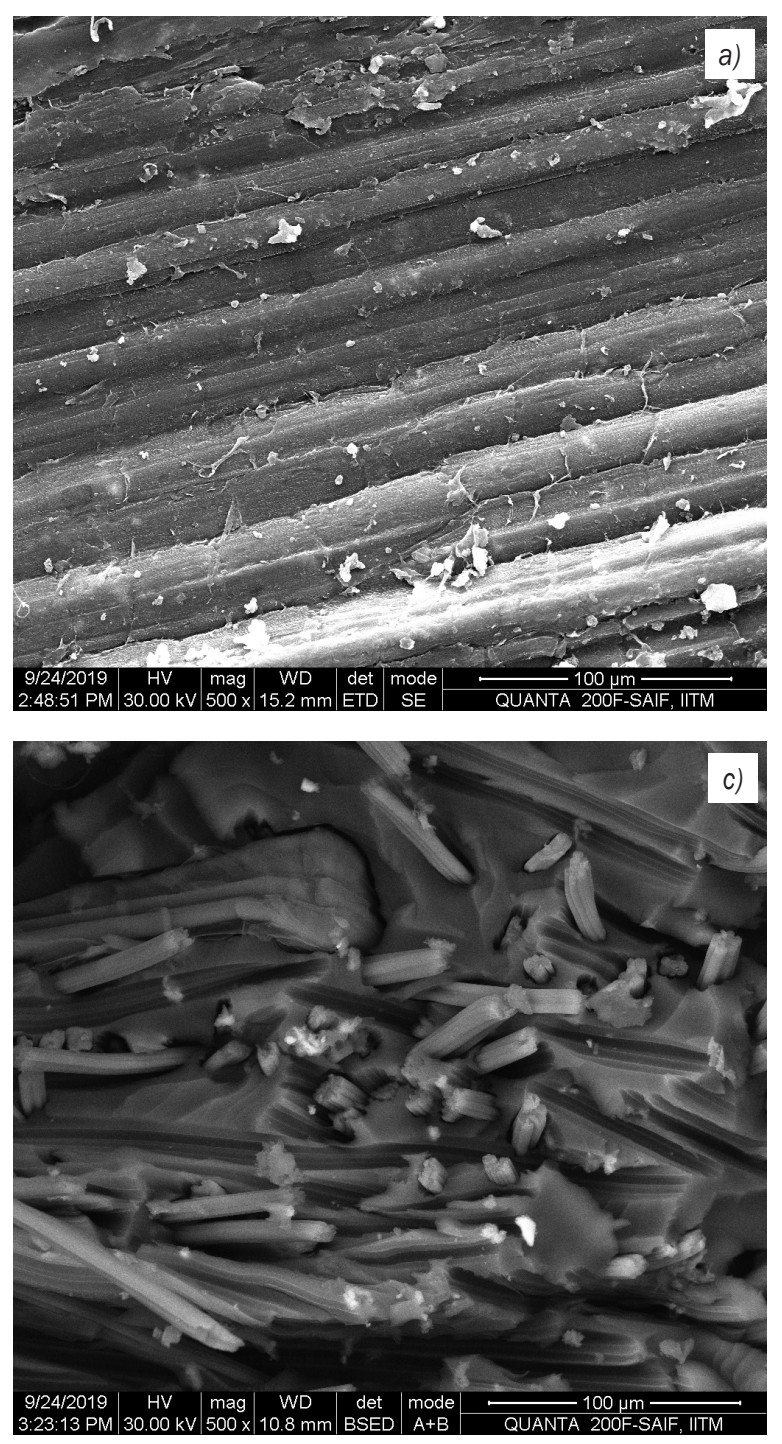

Fig. 1. SEM image of a) Specimen 9 top surface, and b) fractured Specimen 9 of tensile test,

c) fractured Specimen 9 of impact test, and d) fractured Specimen 9 of flexural test

delineates the SEM image of a fractured specimen during a tensile test where the fibre pull out position is visible in the image. Fig. 1c illustrates the SEM image of a fractured specimen of impact test, and Fig. 1d shows the SEM image of the fractured specimen of the flexural test. SEM images show that there are no voids, blowholes, or cracks on the top surface and in the inner layers. These figures reveal that the mixture of the resin and fibre is uniform in all the biohybrid composites.

\subsection{Energy Dispersive X-ray (EDX)}

Fig. 2a represents the distribution of fibres and particulate reinforcement from observed composite
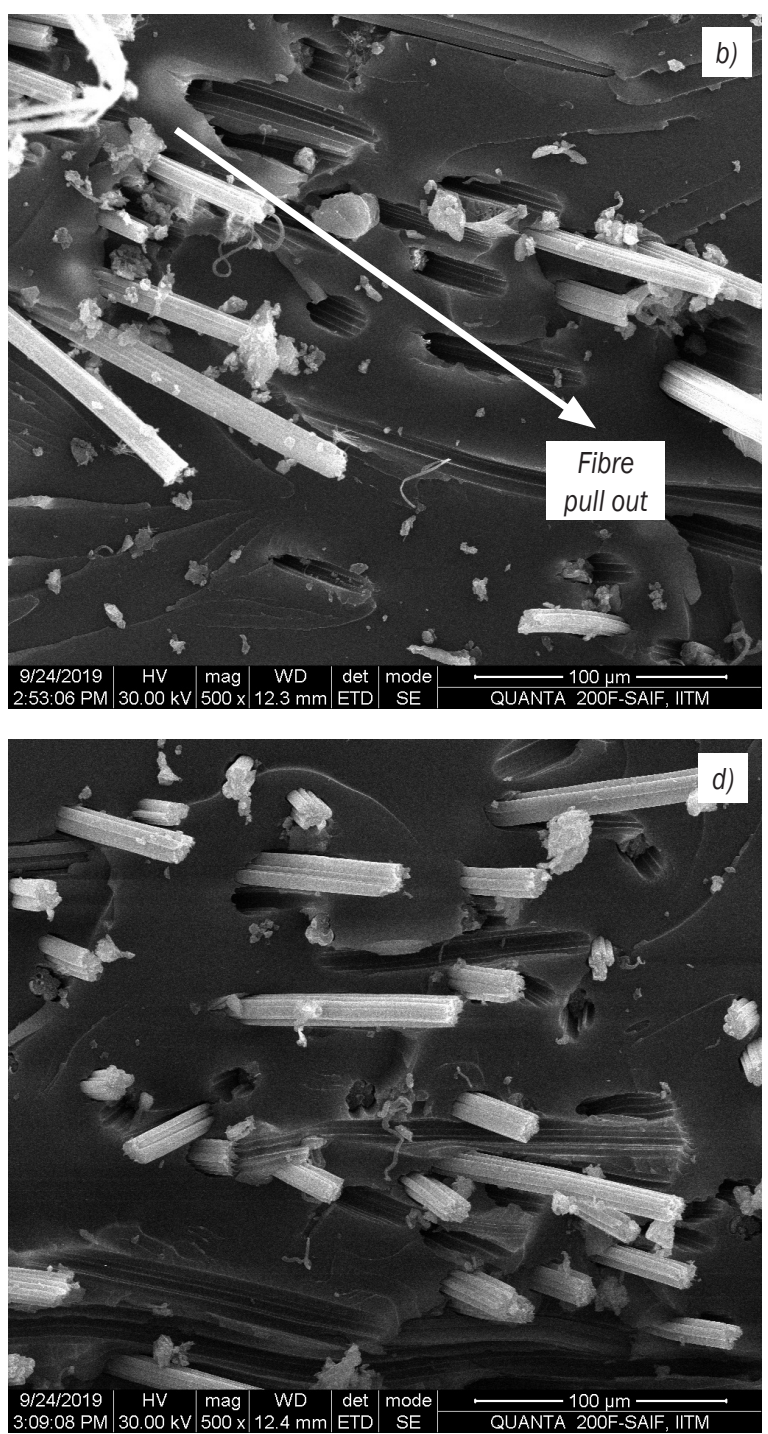

d)

samples; Fig. 2b depicts the energy dispersive X-ray (EDX) spectroscopy of composites material. From the observed EDX analysis, it can be seen that the particles are primarily composed of component mixtures, such as $\mathrm{Ca}, \mathrm{Cl}$, and $\mathrm{C}$. There are numerous trace elements, including $\mathrm{K}, \mathrm{Ca}$, and $\mathrm{Si}$, present in the samples.

The EDX comprises a unique class of fillers that are effectively applicable for polymer matrix as a result of their fine dispersion, inertness, homogeneity, chemical stability, and low water absorption. The presence of $\mathrm{Ca}$ was reported as high, as a result of seashell powdered composite elements deposited in composite samples. Fig. 1a shows that the seashell powder is finely distributed throughout the sample 

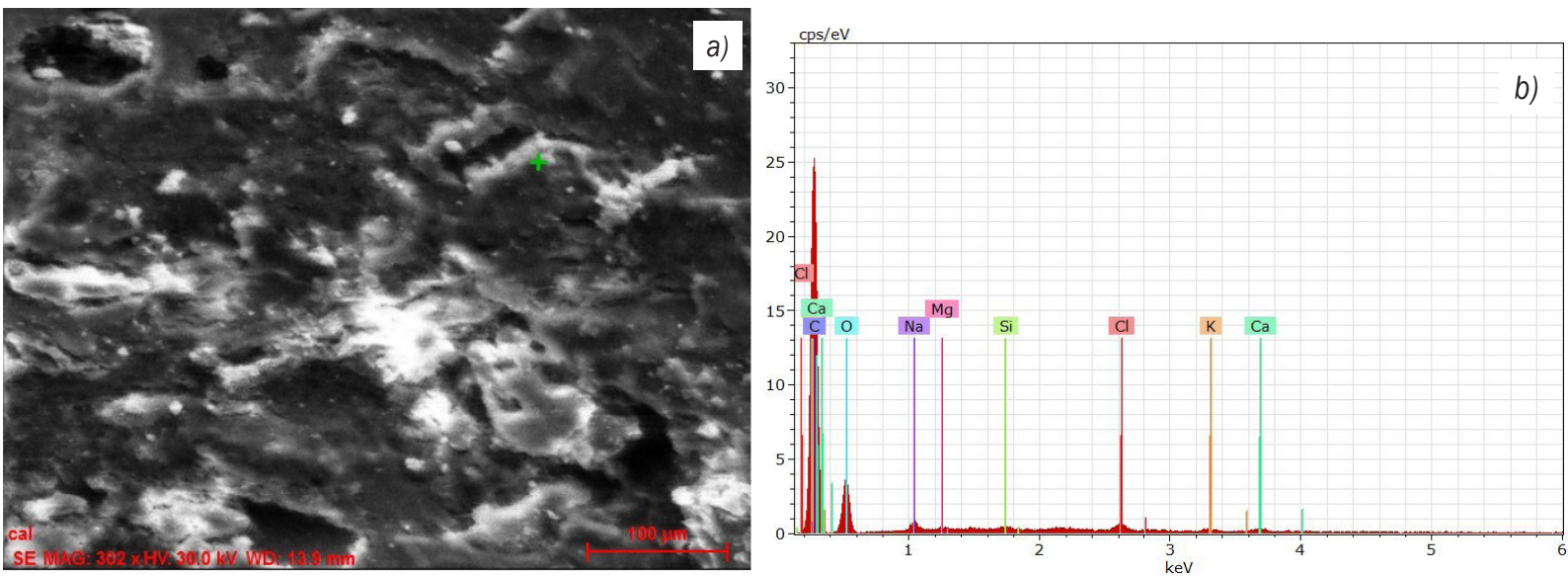

Fig. 2. Composite material Sample 9, a) EDX image, and b) EDX graph

SEM, and it helps to increase the mechanical strength of the composite material.

\subsection{Thermogravimetric Analysis (TGA)}

A special TGA technique has been developed for quantifying the composite mass percentage. TGA curves derived from additives, fibres, and polypropylene are assigned for a composite fraction.

The heating rate is fixed for thermal degradation of single components via using dynamic as well as isothermal segments.

Sample 9 is thermogravimetrically analysed with the existing material to find the percentage of weight loss concerning increasing temperature. The three major weight loss regions are represented in Fig. 3. Fig. 3a displays the TGA results of Sample 9, and Fig. 3 b shows the TGA of the existing material. Table 3 gives the peak temperature at various mass loss percentages and the average temperature is calculated by the obtained values. Sample 9 can withstand even at $451{ }^{\circ} \mathrm{C}$, with $50 \%$ of weight loss and the working temperature in real-time is much less than the calculated temperature. The existing material shows an average temperature of $536.3{ }^{\circ} \mathrm{C}$, and Sample 9 shows an average temperature of $430.6{ }^{\circ} \mathrm{C}$, which is $19.4 \%$ less than that of the existing material. The major reason for this reduction is that the composite is made of NFs.

\subsection{Comparison between the Experimental results and FEA}

As per the ASTM standard tensile, flexural and impact test specimen size, the surface geometry is created using Creo. The created geometry is imported into the ANSYS workbench, and solid jet 4 node 285 element has been chosen for composite laminates. The properties of isotropic fibre-reinforced composites are
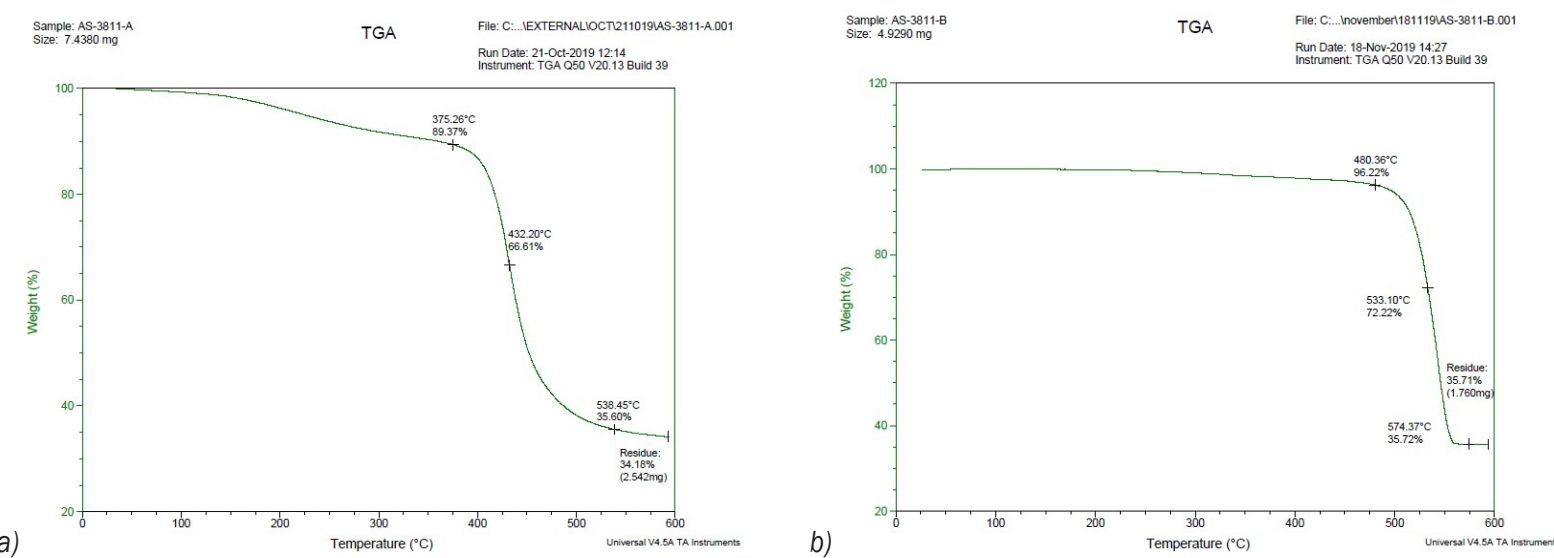

Fig. 3. TGA; a) Sample 9, and b) existing material 
Table 3. The peak temperature at various mass loss percentages

\begin{tabular}{lccccccc}
\hline & \multicolumn{3}{c}{ Peak temperature [ ${ }^{\circ} \mathrm{C}$ ] and (weight [g]) } & \multicolumn{2}{c}{ Mean temperature } \\
\hline Wt. loss [\%] & 10 & 20 & 30 & 40 & 50 & 60 & {$\left[{ }^{\circ} \mathrm{C}\right]$} \\
\hline Sample 9 & $360.6(6.69)$ & $417.3(5.95)$ & $429.0(5.2)$ & $437.6(4.46)$ & $452.0(3.71)$ & $487.0(2.975)$ & 430.6 \\
\hline Existing & $517.0(4.361)$ & $527.0(3.94)$ & $534.6(3.45)$ & $540.7(2.95)$ & $546.0(2.46)$ & $552.7(1)$ & 536.3 \\
\hline
\end{tabular}

Table 4. Boundary conditions

\begin{tabular}{lcccccc}
\hline Properties & $\begin{array}{c}\text { Composite density } \\
{\left[\mathrm{g} / \mathrm{cm}^{3}\right]}\end{array}$ & $\begin{array}{c}\text { Young's modulus } \\
{\left[\mathrm{N} / \mathrm{mm}^{2}\right]}\end{array}$ & Poisson's ratio & $\begin{array}{c}\text { Tensile strength } \\
{[\mathrm{MPa}]}\end{array}$ & $\begin{array}{c}\text { Flexural strength } \\
{[\mathrm{MPa}]}\end{array}$ & $\begin{array}{c}\text { Impact energy } \\
{[\mathrm{J}]}\end{array}$ \\
\hline Sample 9 & 0.99 & $7.57 \times 10^{3}$ & 0.3 & 47.84 & 239.36 & 21 \\
\hline Existing car dash board & 1.03 & $7.27 \times 10^{3}$ & 0.3 & 18.1 & 68.2 & 3.6 \\
\hline
\end{tabular}

theoretically calculated for Sample 9 and the existing material. They are given in Table 4 .

\subsubsection{Tensile Strength Analysis}

Fig. 4 and Table 5 show tensile strength analysis of the existing material and Sample 9.

Table 5. Tensile strength comparison

\begin{tabular}{lcc}
\hline \multirow{2}{*}{ Test conducted } & \multicolumn{2}{c}{ Tensile strength [MPa] } \\
\cline { 2 - 3 } & Existing material & Sample 9 \\
\hline Experimental work result values & 18.1 & 47.84 \\
\hline FEA work result values & 18.57 & 44.73 \\
\hline Variation & 0.47 & 3.11 \\
\hline Variation \% & D 2.56 & I 6.72 \\
\hline
\end{tabular}

The experimental value and the FEA values are within $5 \%$ of variation. As mentioned earlier, Sample 9 exhibits tensile strength, which is $64.1 \%$ higher than the existing material. Experimental values match with the FEA results. FEA results of Sample 9 have the tensile strength of $44.73 \mathrm{MPa}$, and the experimental result is $47.84 \mathrm{MPa}$, which is a $6.72 \%$ increase from the FEA result. The FEA results of the existing material show the tensile strength of $18.57 \mathrm{MPa}$ and the experimental result is $18.1 \mathrm{MPa}$, which is a $2.56 \%$ decrease from the FEA result. In Tables 5, 6, and 7. D stands for decrease and I for increase.

\subsubsection{Flexural Strength Analysis}

Fig. 5 and Table 6 show the flexural strength analysis of the existing material and Sample 9.

Table 6. Flexural strength comparison

\begin{tabular}{lcc}
\hline \multirow{2}{*}{ Test conducted } & \multicolumn{2}{c}{ Flexural strength [MPa] } \\
\cline { 2 - 3 } & Existing material & Sample 9 \\
\hline Experimental work result values & 68.2 & 239.36 \\
\hline FEA work result values & 71.62 & 263.38 \\
\hline Variation & 3.42 & 24.02 \\
\hline Variation \% & D 4.89 & D 9.55 \\
\hline
\end{tabular}

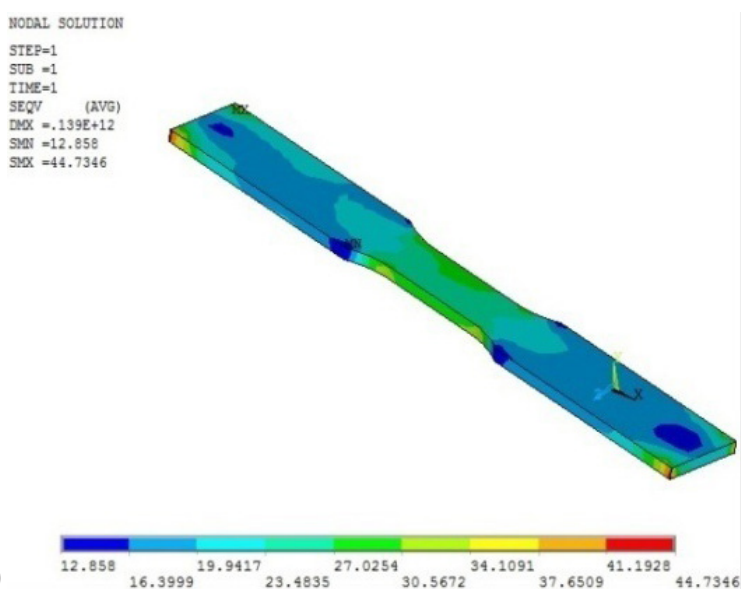

b)

Fig. 4. Tensile strength analysis, a) existing material, b) Sample 9

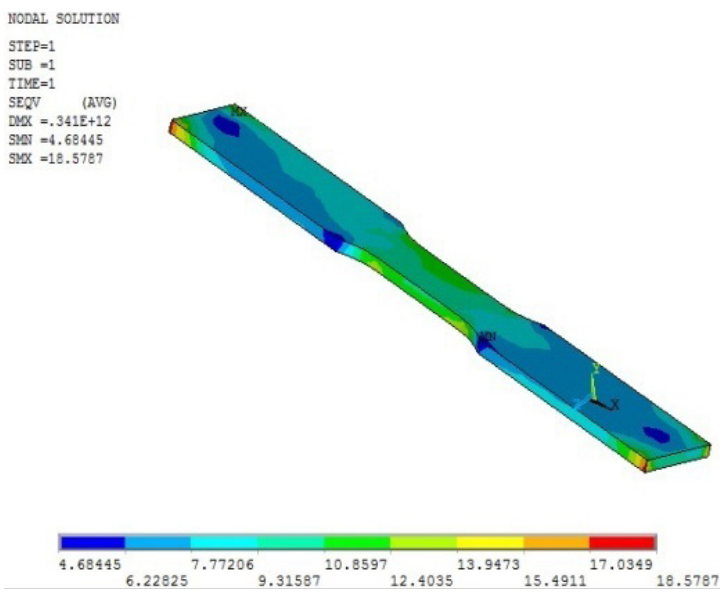

a)

Structural Attributes of Biohybrid Composites Derived Using Hemp, Bamboo, and Jute Fibres: an Alternative Approach ... 


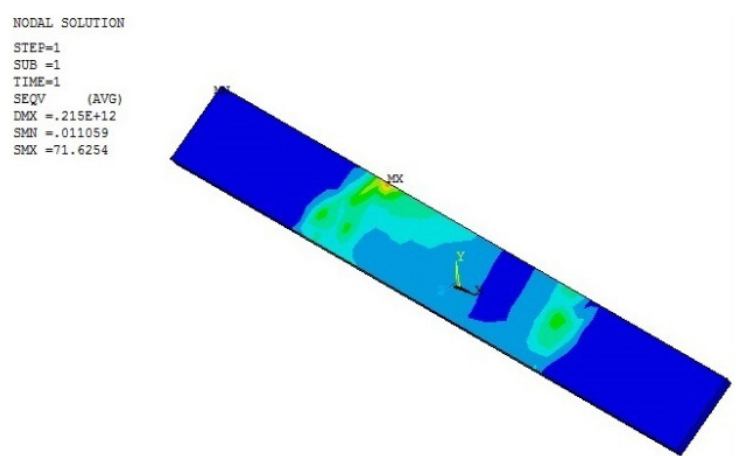

a)

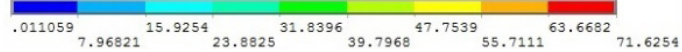

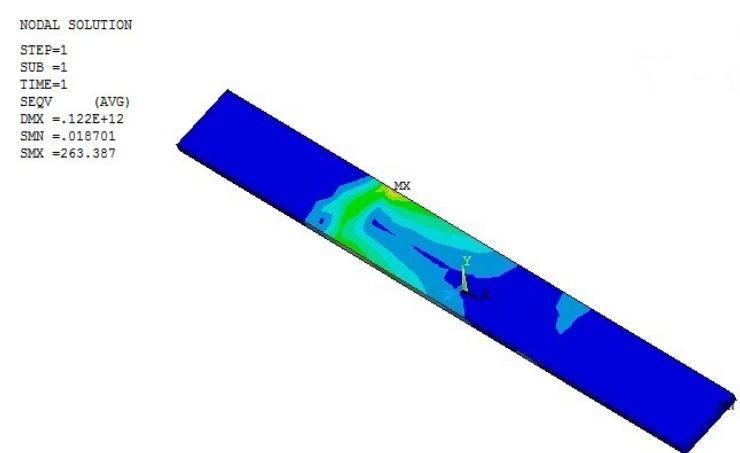

b)

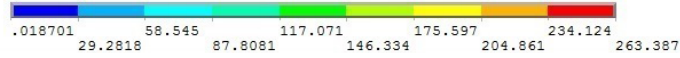

Fig. 5. Flexural strength analysis, a) existing material, b) Sample 9

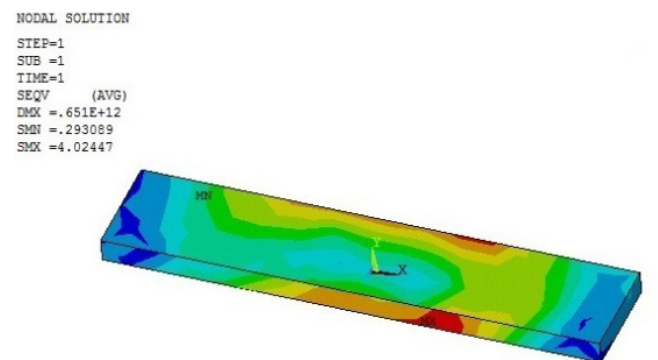

a)

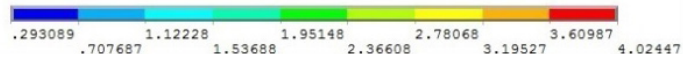

b)
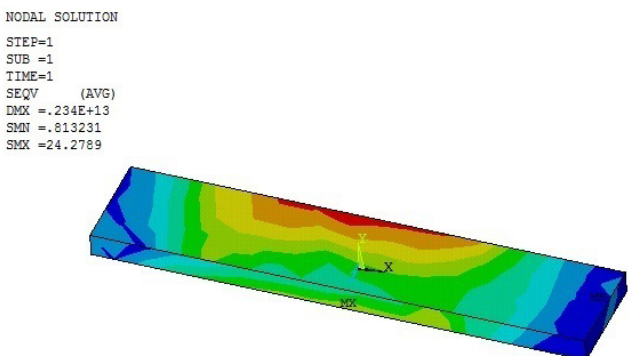

$.813231{ }_{3.42053^{6.02783} 8.63513^{11.2424} 13.8497^{16.457}} 19.0643^{21.6716} 24.2789$

Fig. 6. Impact energy; a) existing material, b) Sample 4

When the experimental values and FEA values are compared, for the existing material, the experimental value of the existing material is $4.89 \%$ less than the FEA results, where as in Sample 9, there is a decrease of $9.55 \%$ compared to the FEA results. As mentioned earlier, Sample 9 exhibits flexural strength that is $150.96 \%$ higher than the existing sample material.

\subsubsection{Impact Energy Analysis}

Fig. 6 and Table 7 shows the impact energy analysis of the existing material and Sample 4.

Table 7. Impact energy comparison

\begin{tabular}{lcc}
\hline \multirow{2}{*}{ Test conducted } & \multicolumn{2}{c}{ Impact energy [J] } \\
\cline { 2 - 3 } & Existing material & Sample 4 \\
\hline Experimental work result values & 3.6 & 21 \\
\hline FEA work result values & 4.02 & 24.27 \\
\hline Variation & 0.42 & 3.27 \\
\hline Variation \% & D 11.02 & D 14.44 \\
\hline
\end{tabular}

The experimental value and the FEA values are compared. It is clear that there is a decrease of 11.02 $\%$ in the existing material and $14.44 \%$ in Sample 4. As mentioned, Sample 4 exhibits impact energy that is 5.83 times higher than that of the existing material. Experimental values match the FEA results. The FEA results of sample 4 show the impact energy of 24.27 $\mathrm{J}$, and its experimental result is $21 \mathrm{MPa}$, whereas the FEA result of the existing material is $4.02 \mathrm{~J}$, and the experimental result is $3.6 \mathrm{~J}$.

\section{CONCLUSIONS}

The composite samples consist of jute, bamboo, and hemp, and they are fabricated. Hybrid composites are subjected to tensile, impact, and flexural testing. Results obtained are compared with the existing material. All the composites exhibit a high value compared to the existing material. Among the nine samples, Sample 9 (20\% hemp, $20 \%$ bamboo, and 60 $\%$ jute) provides the highest values. Thus, for further 
morphological analysis, TGA and FEA analyses are performed with Sample 9, and the results are compared with the existing material results. Consequently, the Sample 9 composite will be the best replacement for the existing material and the same can be utilized for the manufacturing of various vehicle parts.

Based on the results, the major conclusions identified are:

- The tensile strength of Sample 9 composite at 20 $\%$ hemp, $20 \%$ bamboo, and $60 \%$ jute wt. $\%$ fibre, compared to the existing material, is increased by $64.1 \%(47.84 \mathrm{MPa})$ more compared to the existing material $(18.1 \mathrm{MPa})$. These values are high at 29.74 MPa for Sample 9. The unique property of this sample is the presence of high wt. $\%$ of jute.

- The flexural strength of Sample 9 is $239.36 \mathrm{MPa}$, which is $150.96 \%$ higher than that of the existing material $(68.2 \mathrm{MPa})$.

- The impact energy of Sample 9 is five times higher than that of the existing material, and the value for sample 9 is $18.33 \mathrm{~J}$, whereas it is $3.6 \mathrm{~J}$ for the existing material. Thus, it can be concluded that the material can withstand sudden impact without any deformation. This property is essential for the materials of automobile parts.

- Morphological analysis has been carried out to better understand the structure formation and interfacial bonding between the materials.

- TGA results show that the existing material has an average temperature of $536.3{ }^{\circ} \mathrm{C}$, and Sample 9 has an average temperature of $430.6{ }^{\circ} \mathrm{C}$, which is $19.4 \%$ less than the existing material. The major reason for this reduction is that the composite is made of NFs. The working temperature of the interior and exterior parts of the automobiles is below $460.6{ }^{\circ} \mathrm{C}$ and as a result, the material can be used to manufacture automobile parts.

- The FEA results are consistent with the experimental results which show that FEA is the correct tool for testing and evaluating the mechanical behaviour of hybrid structures.

- The results indicate the possibilities of using composites made from NF, such as jute, hemp, and bamboo, as raw materials to produce various automobile parts, which can also be cost-effective and better than the existing material.

\section{REFERENCES}

[1] Robson, J., Hague, J., Newman, G., Jeronimidis, G., Ansell. MP. (1993). Survey of natural materials for use in structural composites as reinforcement and matrices. Report to DTI LINK Structural Composites Committee. Report No. EC/431/92, University of Wales, Cardiff.

[2] Monteiro, S.N., Calado, V., Rodriguez, R.J.S., Margem, F.M. (2012). Thermogravimetric stability of polymer composites reinforced with less common lignocellulosic fibers - an overview. Journal of Materials Research and Technology, vol. 1, no. 2, p. 117-126, Dol:10.1016/S2238-7854(12)70021-2.

[3] Suddell, BC., Evans, WJ., Isaac, DH., Crosky, A. (2002) A Survey into the Application of Natural Fiber Composites in the Automobile Industry. Fourth International Symposium on Natural Polymers and Composites, Sao Pedro, p. 455-461.

[4] Faruk, 0. (2019). Cars from Jute and Other Bio-Fibers, from, http://biggani.com/files_of_biggani/mashiur/interview/ omar_faruk.pdf, accessed on 2019-09-14.

[5] Netravali, A.N., Chabba, S. (2003). Composites get greener. Materials Today, vol. 6, no. 4, p. 22-29, D0l:10.1016/S13697021(03)00427-9.

[6] Bingol, M., Cavdar, K. (2018). New investigations on higher mechanical properties of woven glass fiber reinforced SMC composites. Indian Journal of Engineering and Material Science, vol. 25, no. 4, p. 315-320, nopr.niscair.res.in/ handle/123456789/45263.

[7] Zhang, Y.C., Dai, K., Tang, J.H., Ji, X., Li, Z.M. (2010). Anisotropically conductive polymer composites with a selective distribution of carbon black in an in situ microfibrillar reinforced blend. Materials Letters, vol. 64, no. 13, p. 14301432, D0I:10.1016/j.matlet.2010.03.041.

[8] Li, Z.H., Kobayashi, M. (2004). Plantation future of bamboo in China. Journal of Forestry Research, vol. 15, p. 233-242, DOI:10.1007/BF02911032.

[9] Tan, T., Rahbar, N., Allameh, S.M., Kwofie, S., Dissmore, D., Ghavami, K., Soboyejo, W.O. (2011). Mechanical properties of functionally graded hierarchical bamboo structures. Acta Biomaterialia, vol. 7, no. 10, p. 3796-3803, D0l:10.1016/j. actbio.2011.06.008.

[10] Abutu, J., Lawal, S.A., Ndaliman, M.B., Araga, R.A.L., Adedipe, 0., Choudhury, I.A. (2018). Effects of process parameters on the properties of brake pad developed from seashell as reinforcement material using grey relational analysis. Engineering Science and Technology,an International Journal, vol. 21, no. 4, p. 787-797, D0l:10.1016/j.jestch.2018.05.014.

[11] Gouda, K., Bhowmik, S., Das, B. (2020). Thermomechanical behavior of graphene nanoplatelets and bamboo micro filler incorporated epoxy hybrid composites. Materials Research Express, vol. 7, no. 1, art. ID 015328, D0l:10.1088/20531591/ab67f8.

[12] El Abbassi, F.E., Assarar, M., Ayad, R., Sabhi, H., Buet, S., Lamdouar, N. (2019). Effect of recycling cycles on the mechanical and damping properties of short alfa fibre reinforced polypropylene composite. Journal of Renewable Materials, vol. 7, no. 3, p. 253-267, D0l:10.32604/ jrm.2019.01759.

[13] Li, X., Tabil, L.G., Panigrahi, S. (2007). Chemical treatments of natural fiber for use in natural fiber-reinforced composites: a review. Journal of Polymers and the Environment, vol. 15, p. 25-33, DOI:10.1007/s10924-006-0042-3. 
[14] International Jute Study Group. (2005). Jute, Kenaf \& Roselle Plants, from http://www.jute.org/plant.htm, accesed on 2019-09-26.

[15] Sakaguchi, M., Nakai, A., Hamada, H., Takeda, N. (2000). The mechanical properties of unidirectional thermoplastic composites manufacturing by a micro-braiding technique. Composites Science and Technology, vol. 60, no. 5, p. 717722, D0I:10.1016/S0266-3538(99)00175-X.

[16] Shahzad, A. (2012). Hemp fiber and its composites-a review. Journal of Composite Materials, vol. 46, no. 8, p. 973-986, DOI:10.1177/0021998311413623.

[17] Alarifi, I.M. (2020). Structural analysis of hexagonal and solid carbon fibers composite. Polymer Testing, vol. 84, art. ID 106392, D0I:10.1016/j.polymertesting.2020.106392.

[18] Cavalcanti, D.K.K., Banea, M.D., Neto, J.S.S., Lima, R.A.A., da Silva, L.F.M., Carbas, R.J.C. (2019). Mechanical characterization of intralaminar natural fibre-reinforced hybrid composites. Composites Part B: Engineering, vol. 175, art. ID 107149, D0l:10.1016/j.compositesb.2019.107149.

[19] Kumar, N., Mireja, S., Khandelwal, V., Arun, B., Manik, G. (2017). Light weight high strength hollow glass microspheres and bamboo fiber based hybrid polypropylene composite: A strength analysis and morphological study. Composites Part B: Engineering, vol. 109, p. 277-285, D0l:10.1016/j. compositesb.2016.10.052.

[20] Pickering, K.L., Aruan Efendy, M.G., Le, T.M. (2016). A review of recent developments in natural fibre composites and their mechanical performance. Composites Part A: Applied Science and Manufacturing, vol. 83, p. 98-112, D0l:10.1016/j. compositesa.2015.08.038.

[21] Ichazo, M.N., Albano, C., Gonzalez, J., Perera, R., Candal, M.V. (2001). Polypropylene/wood flour composites treatments and properties. Composites Structures, vol. 54, no. 2-3. p. 207214, D0l:10.1016/S0263-8223(01)00089-7.

[22] Mwaikambo, L.Y., Ansell, M.P. (2002). Chemical modification of hemp, sisal, jute and kapok fibers by alkalization. Journal of Applied Polymer Science, vol. 84, no. 12, p. 2222-2234, DOI:10.1002/app.10460.

[23] Sgriccia, N., Hawley, M.C., Misra, M. (2008). Characterization of natural fiber surfaces and natural fiber composites. Composites Part A: Applied Science and Manufacturing, vol. 39, no. 10, p. 1632-1637, D0l:10.1016/j. compositesa.2008.07.007.

[24] Venkateshwaran, N., Elaya Perumal, A., Alavudeen, A., Thiruchitrambalam, M. (2011). Mechanical and water absorption behaviour of banana/sisal reinforced hybrid composites. Materials \& Design, vol. 32, no. 7, p. 4017-4021, DOI:10.1016/j.matdes.2011.03.002.
[25] Nam, T.H., Ogihara, S., Tung, N.H., Kobayashi, S. (2011). Effect of alkali treatment on interfacial and mechanical properties of coir fibre reinforced poly (butylene succinate) biodegradable composites. Composites Part B: Engineering, vol. 42, no. 6, p. 1648-1656, D0l:10.1016/j.compositesb.2011.04.001.

[26] Sepe, R., Bollino, F., Boccarusso, L., Caputo, F. (2018). Influence of chemical treatments on mechanical properties of hemp fibre reinforced composites. Composites Part B: Engineering, vol. 133, p. 210-217, D0l:10.1016/j. compositesb.2017.09.030.

[27] Cartié, D.D.R., Irving, P.E. (2002). Effect of resin and fibre properties on impact and compression after impact performance of CFRP. Composites Part A: Applied Science and Manufacturing, vol. 33, no. 4, p. 483-493, Dol:10.1016/ S1359-835X(01)00141-5.

[28] Vyazovkin, S., Koga, N., Schick, C. (2018). Handbook of Thermal Analysis and Calorimetry, Recent Advances, Techniques and Applications. vol. 6, p. 1-842, Elsevier, Amsterdam, DOI:10.1016/B978-0-444-64062-8.10000-2.

[29] Mertani, B.MčB., Keskes, B., Tarfaoui, M. (2019). Numerical study on the compressive behaviour of an aluminium honeycomb core. Materials and Technology, vol. 53, no. 2, p. 199-206, D0l:10.17222/mit.2018.028.

[30] Gutiérrez, M.C., De Paoli, M.A., Felisberti, M.I. (2014). Cellulose acetate and short curaua fibers biocomposites prepared by large scale processing: Reinforcing and thermal insulating properties. Industrial Crops \& Products, vol. 52, p. 363-372, D0I:10.1016/J.indcrop.2013.10.054.

[31] Arunachalam, K., Sundara Pandian, G. (2016). Modeling and analysis of clutch facing made up of biodegradable coir fibre based composite material. Polymers \&Polymer Composites, vol. 24, no. 7, p. 463-468, DOI:10.1177/096739111602400703.

[32] Rao, B.R., Raju, V.R., Rao, K.M. (2015). Effect of fibre shape on transverse thermal conductivity of unidirectional composites. Sadhana, vol. 40, p. 503-513, D0I:10.1007/s12046-0140323-9.

[33] Srinivasan, S.P., Raajarajan, L. (2017). Wear rate and surface coating optimization of coconut coir-based polymer using fuzzy logic. Sadhana, vol. 42, p. 281-290, D0l:10.1007/s12046017-0601-4.

[34] Tanguy, M., Bourmaud, A., Beaugrand, J., Gaudry, T., Baley, C. (2018). Polypropylene reinforcement with flax or jute fibre; Influence of microstructure and constituents properties on the performance of composite. Composites Part B: Engineering, vol. 139, p. 64-74, D0I:10.1016/j.compositesb.2017.11.061.

[35] Sullins, T., Pillay, S., Komus, A., Ning, H. (2017). Hemp fiber reinforced polypropylene composites: The effects of material treatments. Composites Part B: Engineering, vol. 114, p. 1522, Dol:10.1016/j.compositesb.2017.02.001. 